\title{
Tomato leaf curl Gujarat virus, a New Begomovirus Species Causing a Severe Leaf Curl Disease of Tomato in Varanasi, India
}

\author{
S. Chakraborty, P. K. Pandey, M. K. Banerjee, G. Kalloo, and C. M. Fauquet
}

First and fifth authors: International Laboratory for Tropical Agricultural Biotechnology, Donald Danforth Plant Science Center, 975 N. Warson Road, St. Louis, MO 63132; and second, third, and fourth authors: Indian Institute of Vegetable Research, 1 Gandhinagar (Naria), PB. 5002, PO-BHU, Varanasi, 221 005, Uttar Pradesh, India. Accepted for publication 18 June 2003.

\begin{abstract}
Chakraborty, S., Pandey, P. K., Banerjee, M. K., Kalloo, G., and Fauquet, C. M. 2003. Tomato leaf curl Gujarat virus, a new Begomovirus species causing a severe leaf curl disease of tomato in Varanasi, India. Phytopathology 93:1485-1495.

The biological and molecular properties of Tomato leaf curl Gujarat virus from Varanasi, India (ToLCGV-[Var]) were characterized. ToLCGV[Var] could be transmitted by grafting and through whitefly transmission in a persistent manner. The full-length genome of DNA-A and DNA-B of ToLCGV-[Var] was cloned in pUC18. Sequence analysis revealed that DNA-A (AY190290) is 2,757 bp and DNA-B (AY190291) is 2,688 bp in length. ToLCGV-[Var] could infect and cause symptoms in tomato, pepper, Nicotiana benthamiana, and N. tabacum when partial tandem dimeric constructs of DNA-A and DNA-B were co-inoculated by particle bombardment. DNA-A alone also is infectious, but symptoms were milder and took longer to develop. ToLCGV-Var virus can be transmitted through sap inoculation from infected tomato plants to the above-men-

tioned hosts causing the same symptoms. Open reading frames (ORFs) in both DNA-A and DNA-B are organized similarly to those in other begomoviruses. DNA-A and DNA-B share a common region of $155 \mathrm{bp}$ with only $60 \%$ sequence identity. DNA-B of ToLCGV-[Var] shares overall $80 \%$ identity with DNA-B of Tomato leaf curl New Delhi virus-Severe (ToLCNDV-Svr) and 75\% with ToLCNDV-[Lucknow] (ToLCNDV[Luc]). Comparison of DNA-A sequence with different begomoviruses indicates that ToLCGV-[Var] shares $84 \%$ identity with Tomato leaf curl Karnataka virus (ToLCKV) and 66\% with ToLCNDV-Svr. ToLCGV[Var] shares a maximum of $98 \%$ identity with another isolate of the same region (ToLCGV-[Mir]; AF449999) and 97\% identity with one isolate from Gujarat (ToLCGV-[Vad]; AF413671). All three viruses belong to the same species that is distinct from all the other geminivirus species described so far in the genus Begomovirus of the family Geminiviridae. The name Tomato leaf curl Gujarat virus is proposed because the first sequence was taken from an isolate of Gujarat, India.
\end{abstract}

Plant-infecting geminiviruses belong to the family Geminiviridae. They have circular, single-stranded DNA genomes and are encapsidated within geminate particles. Based on genome organization, host range, and insect vector, geminiviruses are divided into four genera: Mastrevirus, Curtovirus, Topocuvirus, and Begomovirus $(15,21)$. The members of the genus Begomovirus are transmitted by whiteflies (Bemisia tabaci Gennadius) and most begomoviruses possess a bipartite genome of two components (DNA-A and DNA-B) that infect dicotyledonous plant species (21). However, there are several examples of begomoviruses that possess a monopartite genome, with only DNA-A as a single genomic component $(2,6,8,12,16,17)$.

Tomato leaf curl disease (TLCD) occurs in many tomato-producing regions of the world, including India. Characterized by severe leaf curling, shrinking of tomato leaves, and stunted plant growth, TLCD is caused by geminiviruses (genus Begomovirus, family Geminiviridae) and is transmitted by whitefly. Geminiviruses are a major constraint for the successful cultivation of tomato in the tropics and subtropics $(6,10)$. Several geminivirus species infecting tomatoes from the Old World have been characterized. Monopartite tomato-infecting whitefly-transmitted geminiviruses (WTGs), such as Tomato yellow leaf curl virus from Israel (TYLCV) (17), Tomato yellow leaf curl Sardinia virus from Italy (TYLCSV-[Sic]) (12), and Tomato leaf curl virus from Australia (ToLCV) (8), are monopartite and therefore do not have

Corresponding author: C. M. Fauquet; E-mail address: iltab@danforthcenter.org

Publication no. P-2003-0929-01R

(C) 2003 The American Phytopathological Society a B component. On the contrary, Tomato yellow leaf curl Thailand virus (TYLCTHV) is a monopartite/bipartite virus that possesses a B component (20) which enhances symptom severity caused by the A component alone.

TLCD is a very significant problem for tomato-growing regions in India. Since the first report of the occurrence of a leaf curl disease of tomato in India by Vasudev and Sam Raj (24), attempts have been made to characterize the causal agent based on biological and molecular properties. There are several reports of species or strains of tomato leaf curl geminiviruses causing TLCD in India. The species from Northern India, such as Tomato leaf curl New Delhi virus from New Delhi (ToLCNDV) (GenBank Accession Nos. U15015 and U15016) (18) and from Lucknow (ToLCNDV-[Luc]; GenBank Accession Nos. Y16421 and X89653) (22), are bipartite in nature and both genomic components are required for infection to occur $(18,22)$. Isolates reported from Southern India apparently possess only the DNA-A component $(2,16)$. Two isolates of Tomato leaf curl Bangalore virus (ToLCBV) from Bangalore have been characterized $(11,16)$. With the exception of Tomato leaf curl Karnataka virus (ToLCKV), for which infectivity has been demonstrated (2), neither infectivity nor the association of a DNA-B component has been reported. DNA-A of one isolate of TLCD from Gujarat (AF413671) and one from Mirzapur (a district adjoining Varanasi) (AF449999) has been sequenced, but no other information has been provided regarding either of these isolates. During November 2001, a severe TLCD, manifesting yellowing of the leaf lamina with upward leaf curling, leaf distortion, shrinking of the leaf surface, and stunted plant growth, was observed in the research farm of the Indian Institute of Vegetable Research and surrounding tomato-growing areas in the Varanasi and Mirzapur districts of eastern Uttar Pradesh, India, 
causing yield losses up to $100 \%$. Here, we describe a new Begomovirus isolate from tomato plants exhibiting leaf curl symptoms from Varanasi, India belonging to a new geminivirus species. This sap-transmissible Begomovirus isolate is mono-bipartite in nature, indicating that DNA-A alone is infectious, but association with DNA-B increases symptom severity and shortens incubation period. The new species has been named Tomato leaf curl Gujarat virus (ToLCGV) and ToLCGV-[Varanasi] (ToLCGV-[Var]) is proposed as the name of the isolate characterized here.

\section{MATERIALS AND METHODS}

Virus source and maintenance. Leaves from tomato plants (Lycopersicon esculentum L.) manifesting leaf curling, diminution of the leaf surface, and yellowing symptoms were collected from a severely infected field in the experimental farm of the Indian Institute of Vegetable Research, Varanasi, Uttar Pradesh, India, in 2001 (Fig. 1A). The virus culture was maintained on the susceptible tomato cv. Punjab Chuhara through grafting. The culture of nonviruliferous whiteflies was maintained on eggplant (Solanum melongena $\mathrm{L}$.), which is immune to TLCD. A culture of ToLCGV[Var] was established in the greenhouse by whitefly transmission on susceptible tomato cvs. Punjab Chuhara and Pusa Ruby, and was maintained by periodic transfer on tomato. Adult nonviruliferous whiteflies were given an acquisition access period (AAP)
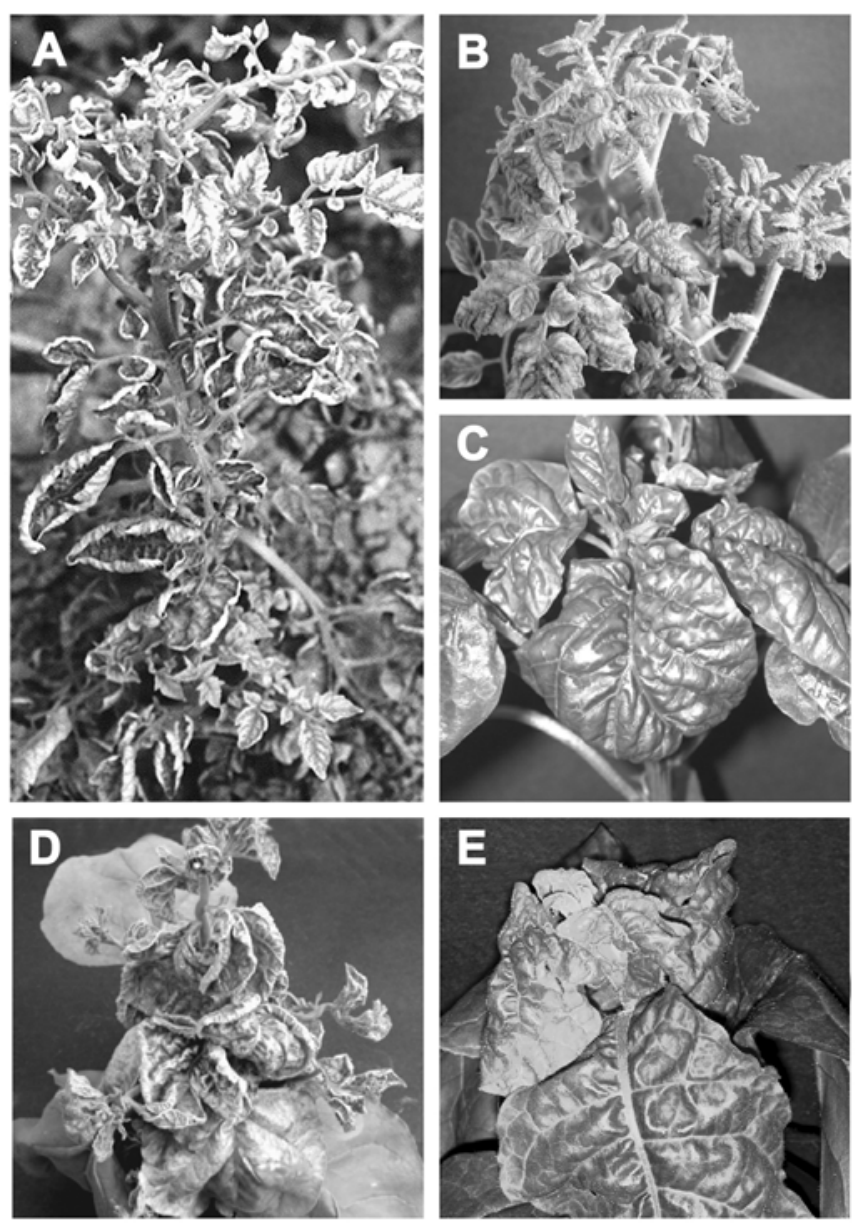

Fig. 1. Symptoms induced by Tomato leaf curl Gujarat virus-[Varanasi] (ToLCGV-[Var]). A, Tomato cv. Punjab Chuhara showing yellowing of leaf lamina and leaf curl symptoms under natural conditions. B to E, Test plants showing systemic symptoms after biolistic inoculation with ToLCGV-[Var] DNA-A and DNA-B. B, Tomato cv. Organ Spring showing symptoms at 21 days postinoculation (dpi). C, Pepper cv. California Wonder showing leaf curling symptoms at 10 dpi. D, Symptoms on Nicotiana benthamiana at $21 \mathrm{dpi}$. E, Tobacco cv. Xanthi showing leaf curling symptoms at $10 \mathrm{dpi}$. of $24 \mathrm{~h}$ on leaves of infected plants and then released on healthy test plants (eight whiteflies per plant) for an inoculation access period (lAP) of $24 \mathrm{~h}$ unless otherwise specified. After inoculation, whiteflies were killed with sprayed insecticide $(0.05 \%$ Decis 2.8 EC) and the plants were kept in an insect-proof glasshouse up to 30 days after inoculation.

Virus-vector relationship. Tomato cv. Pusa Ruby was used as the virus source and adult whiteflies were used for the transmission studies. Two-week-old seedlings of the susceptible tomato cv. Pusa Ruby were used as test plants for inoculation studies. Eight virus-free whiteflies were given an AAP of $0.5,1,3,6,9,12,15$, or $24 \mathrm{~h}$ on ToLCGV-[Var]-infected tomato cv. Pusa Ruby, followed by a 24-h IAP. The minimum IAP was determined by allowing eight viruliferous whiteflies for a 24-h AAP on the infected source plants, followed by IAPs of $0.5,1,3,6,9,12$, 15, or $24 \mathrm{~h}$ on test plants. To determine transmission efficiency, viruliferous whiteflies were caged with test plants $(1,2,3,4,5,8$, or 10 insects per plant) for a 24 -h AAP and IAP each. The persistence of the virus in the vector was measured by the serial transfer of individual whiteflies to virus-free tomato seedlings at 12-h intervals for 12 consecutive days. Test plants were scored for infection by the appearance of disease symptoms.

Cloning of viral genome. Tomato plants (cv. Punjab Chuhara) showing typical leaf curl symptoms 12 days postinoculation (dpi) were collected and stored at $-70^{\circ} \mathrm{C}$. The total DNA from ToLCGV-[Var]-infected tomato leaves was isolated by the cetyltrimethylammonium bromide method (22) followed by concentration of super-coiled DNA by the alkaline lysis method (1). The replicative form (RF) of the genomic DNA was used as template for polymerase chain reaction (PCR) amplification using degenerate primers for general detection of begomoviruses (25). RF DNA (earlier isolated through alkaline lysis method) was digested with restriction endonucleases (EcoRI, HindIII, PstI, BamHI, or XbaI) and then cloned into pUC18 previously linearized with the same enzymes.

Infectivity of cloned DNAs. For the purpose of infectivity, the genomic components were subcloned as partial tandem repeats in pUC18. The HindIII (92)-EcoRI $(1,459)$ fragment of ToLCGV[Var] DNA-A (pSCHA1) was cloned into pUC18 and the fulllength HindIII fragment then was inserted to produce a 1.6-mer tandem repeat called pTGVA. The XbaI $(2,547)-E c o$ RI $(1,654)$ fragment of ToLCGV-[Var] DNA-B (pSCXB1) was cloned into pUC18 and the full-length fragment then was inserted at the XbaI site to produce a 1.8-mer tandem repeat called pTGVB1. For another full-length DNA-B (pSCXB2), a similar strategy was used to develop 1.8-mer tandem repeat constructs at $\mathrm{XbaI}$ (hereafter referred to as pTGVB2). Insert orientation within partial tandem repeats was confirmed by restriction digestion with appropriate enzymes.

In preliminary experiments, the tandemly repeated inserts of ToLCGV-[Var] clones pTGVA and pTGVB1 $(0.5 \mu \mathrm{g}$ per construct per plant) were mechanically inoculated onto Nicotiana benthamiana, tomato cv. Organ Spring, and N. tabacum cv. Xanthi plants. Subsequently, Nicotiana spp. and tomato cv. Organ Spring were inoculated with partial tandemly repeated constructs using a BioRad helium-driven particle accelerator. DNA and gold particles $(0.2 \mu \mathrm{g}$ DNA coated with $0.6 \mathrm{mg}$ of gold particles per plant) were prepared as described by Klein et al. (14) and were accelerated at 1,100 psi onto young leaves of 2-week-old seedlings. The plants were maintained at periods of $16 \mathrm{~h}$ light, $8 \mathrm{~h}$ dark for 6 weeks, scored for symptoms, and analyzed for viral DNA. Tandemly repeated constructs of DNA-A alone also were delivered by the biolistic method onto $N$. benthamiana and tomato cv. Organ Spring.

The experimental host range of cloned ToLCGV-[Var] plasmids containing tandem repeats of the virus genome (pTGVA and pTGVB1) was determined via biolistic inoculation of test plants. Plants used in the host range study were tomato (Lycopersicon 
esculentum cvs. Flora Dade, Geneva 11, Geneva 790, and Organ Spring), N. benthamiana, N. glutinosa, N. tabacum cv. Xanthi, bean (Phaseolus vulgaris cv. Improved Tender Green), pepper (Capsicum annuum cv. California Wonder), cotton (Gossypium hirsutum cv. Stanville), and okra (Abelmoschus esculentus cv. Dwarf Green). Inoculated plants were maintained in the greenhouse at $28 \pm 2^{\circ} \mathrm{C}$ for 45 days. Viral DNAs in the youngest leaves were detected by PCR using ToLCGV-[Var]-specific primers (as mentioned below).

Mechanical inoculation. ToLCGV-[Var] inocula were prepared by grinding symptomatic leaf tissues from tomato (cv. Organ Spring, previously infected with cloned DNAs pTGVA and pTGVB1, through the biolistic method) in ice-cold $0.1 \mathrm{M}$ potassium phosphate buffer, $\mathrm{pH} 7.0(1: 2, \mathrm{wt} / \mathrm{vol})$ containing $0.15 \%$ sodium sulfite. First, the young leaves of test plants were dusted with carborundum powder (400 mesh), followed by rubbing with the sap inoculum using a cotton-wrapped stick. The test plants of tomato cv. Organ Spring, N. benthamiana, N. tabacum cv. Xanthi, pepper (cv. California Wonder), okra (cv. Dwarf Green), French bean (cv. Improved Tender Green), cotton (cv. Stanville), and $N$. glutinosa were kept in the greenhouse up to 6 weeks for symptom expression and detection of viral DNA by PCR (described below).

PCR detection. Total DNA was extracted from test plants and tomato plants following the method of Dellaporta et al. (7). DNAA-specific oligonucleotide primers (GAv50 TAACTGACAAAGACATGCGGA and GAc1122 AACATTTGTAGACAGTTCAAATAT) and DNA-B-specific primer combinations (GBv74 CTCATCCGATTTGCAACACGT and GBc1280 AATTGCATTTTCAAATTCCATGTTCGTACA) were used in PCR. The PCR conditions for amplification in both cases were an initial strand separation at $94^{\circ} \mathrm{C}$ for $2 \mathrm{~min}$ and then 30 cycles of $1 \mathrm{~min}$ at $94^{\circ} \mathrm{C}$, $1 \mathrm{~min}$ at $55^{\circ} \mathrm{C}$, and $1 \mathrm{~min}$ at $72^{\circ} \mathrm{C}$, followed by a final extension period of $10 \mathrm{~min}$ at $72^{\circ} \mathrm{C}$. PCR products were resolved on a $1.2 \%$ agarose gel.

Sequence analysis. The complete DNA sequences of ToLCGV[Var] DNA-A and DNA-B were determined by the dideoxynucleotide chain termination method using an ABI automatic sequencer with primers specific to either cloning vectors or established viral sequences. Sequences obtained were analyzed using the DNASTAR package (version 1.02; DNASTAR, Madison, WI) for the Apple Macintosh computer. The multiple sequence alignment (MegAlign 3.11) program within the DNASTAR package was used to align DNA-A ToLCGV-[Var] sequences with 71 distinct Begomovirus sequences representing 64 distinct virus species. In addition, a complete sequence analysis for each open reading frame (ORF) and intergenic region (IR) was done for the closest 21 virus species related to ToLCGV. All the sequences used for this analysis were obtained from GenBank; the accession numbers of the 22 virus species subset used are listed in Table 1. Dendrograms and corresponding distance matrices were developed using the Clustal method with a weighted residue table. The program PAUP 4.0 (23) was used to generate the bootstrap test performed on the obtained multiple alignments with 100 iterations.

Pairwise analysis method. According to the most recent guidelines of the ICTV Geminiviridae Study Group (9), two geminivirus sequences sharing more than $89 \%$ identity of their A component sequences can be considered strains or isolates of the same species; otherwise, they may be considered different species. However, most of the viruses sharing between 80 and $90 \%$ are usually recombinants; therefore, we here consider as a reference for this analysis different virus species sharing less than $80 \%$ identity. Pairwise sequence comparison profiles are done between sequences of different species and of different strains with an average profile relevant for the considered cluster of viruses cal-

TABLE 1. GenBank accession numbers of selected Begomovirus sequences from Asia used in this study for analysis

\begin{tabular}{|c|c|c|c|}
\hline \multirow[b]{2}{*}{ Begomoviruses } & \multicolumn{2}{|c|}{ Genomes } & \multirow[b]{2}{*}{ Abbreviation $^{\mathrm{a}}$} \\
\hline & DNA-A & DNA-B & \\
\hline Ageratum enation virus & AJ437618 & $\ldots$ & $\mathrm{AEV}$ \\
\hline Ageratum yellow vein Sri Lanka virus & AF314144 & $\ldots$ & AYVSLV \\
\hline Bhendi yellow vein mosaic virus-[Madurai] & AF241479 & $\ldots$ & BYVMV \\
\hline Chilli leaf curl virus-[Multan] & AF336806 & $\ldots$ & ChiLCuV-(Mul) \\
\hline Cotton leaf curl Alabad virus-[802a] & AJ002455 & $\ldots$ & CLCuAV-(802a) \\
\hline Cotton leaf curl Kokhran virus-[Faisalabad1] & AJ496286 & $\ldots$ & CLCuKV-(Fai1) \\
\hline Cotton leaf curl Multan virus-[62] & AJ002447 & $\ldots$ & CLCuMV-(62) \\
\hline Cotton leaf curl Rajhastan virus & AF363011 & $\ldots$ & CLCuRV \\
\hline Croton yellow vein mosaic virus & AJ507777 & $\ldots$ & CYVMV \\
\hline Malvastrum yellow vein virus-[Y47] & AJ457824 & $\ldots$ & MYVV-(Y47) \\
\hline Mungbean yellow mosaic Indian virus & AF126406 & AF142440 & MYMIV \\
\hline Mungbean yellow mosaic virus & D14703 & D14704 & MYMV \\
\hline Okra yellow vein mosaic virus-[201] & AJ002451 & $\ldots$ & OYVMV-(201) \\
\hline Papaya leaf curl virus & Y15934 & $\ldots$ & $\mathrm{PaLCuV}$ \\
\hline Pepper leaf curl Bangladesh virus & AF314531 & $\ldots$ & PepLCBV \\
\hline Squash leaf curl China virus & AB027465 & $\ldots$ & SLCCNV \\
\hline Tobacco curly shoot virus-[Y1] & AF240675 & $\ldots$ & TbCSV-(Y1) \\
\hline Tomato leaf curl Bangalore virus & Z48182 & $\ldots$ & ToLCBV \\
\hline Tomato leaf curl Bangalore virus-[Ban4] & AF165098 & $\ldots$ & ToLCBV-(Ban4) \\
\hline Tomato leaf curl Bangalore virus-[Ban5] & AF295401 & $\ldots$ & ToLCBV-(Ban5) \\
\hline Tomato leaf curl Bangalore virus-[Kolar] & AF428255 & $\ldots$ & ToLCBV-(Kol) \\
\hline Tomato leaf curl Bangladesh virus & AF188481 & $\ldots$ & ToLCBDV \\
\hline Tomato leaf curl Gujarat virus-[Vadodara] & AF413671 & $\ldots$ & ToLCGV-(Vad) \\
\hline Tomato leaf curl Gujarat virus-[Varanasi] & AY190290 & AY190291 & ToLCGV-(Var) \\
\hline Tomato leaf curl Gujarat virus-[Mirzapur] & AF449999 & $\ldots$ & ToLCGV-(Mir) \\
\hline Tomato leaf curl Karnataka virus & U38239 & $\ldots$ & ToLCKV \\
\hline Tomato leaf curl Malaysia virus & AF327436 & $\ldots$ & ToLCMV \\
\hline Tomato leaf curl New Delhi virus-Mild & U15016 & $\ldots$ & ToLCNDV-Mld \\
\hline Tomato leaf curl New Delhi virus-Severe & U15016 & U15016 & ToLCNDV-Svr \\
\hline Tomato leaf curl New Delhi virus-[Lucknow] & Y16421 & X89653 & ToLCNDV-(Luc) \\
\hline Tomato leaf curl New Delhi virus-[Luffa] & AF102276 & $\ldots$ & ToLCNDV-(Luf) \\
\hline Tomato leaf curl Sri Lanka virus & AF274349 & $\ldots$ & ToLCSLV \\
\hline Tomato yellow leaf curl Thailand virus-[1] & X63015 & X63016 & TYLCTHV-(1) \\
\hline Tomato yellow leaf curl Thailand virus-[2] & AF141922 & AF141897 & TYLCTHV-(2) \\
\hline
\end{tabular}

${ }^{a}$ Begomoviruses are named as per ICTV guidelines (9). 
culated for these two categories using increments of 50 nucleotides (nt). A standard deviation value for each segment is calculated and minimum and maximum values corresponding to two standard deviation values also are calculated. Each profile of the chosen pairwise analysis for putative recombinant sequences then is compared to the species average profile and the association of each 50-nt fragment of the chosen pairwise comparison then is examined. Segments having a percentage identity differing from more than two standard deviation values are considered as not belonging to the species level and, therefore, constitute a putative recombinant fragment. For each pairwise analysis, a putative recombination percentage of the genome length is calculated and a corresponding map can be drawn. A posteriori, it is verified that the species and strains chosen for the species and strain average curves are $100 \%$ nonrecombinant with the studied viruses.

For this analysis, DNA-A of 22 different virus isolates, each representing a species originating from the Asian region (Table 1), and the DNA-B of four TLCD-causing geminiviruses were compared.

\section{RESULTS}

Virus-vector relationship. Single viruliferous whiteflies successfully transmitted ToLCGV-[Var] to tomato plant cv. Pusa Ruby. After a 24-h AAP and 24-h IAP, from 9 to 12 out of 20 test plants (45 to $60 \%$ transmission) were infected using a single whitefly (data not shown). A minimum of five whiteflies per test plant was required to achieve $100 \%$ transmission (data not shown). Groups of eight whiteflies failed to transmit ToLCGV[Var] (Table 2) when allowed an AAP of $0.5 \mathrm{~h}$. However, success-

TABLE 2. Effect of acquisition access period (AAP) and inoculation access period (IAP) on whitefly transmission of Tomato leaf curl Gujarat virus[Varanasi] (ToLCGV-[Var]) to tomato cv. Pusa Ruby seedlings a

\begin{tabular}{lcc}
\hline & \multicolumn{2}{c}{ Infected plant/inoculated plant $(\%)^{\mathrm{b}}$} \\
\cline { 2 - 3 } Time $(\mathrm{h})$ & AAP & 1 AP \\
\hline 0.5 & $0 / 14(0)$ & $0 / 15(0)$ \\
1 & $4 / 15(27)$ & $3 / 15(20)$ \\
3 & $6 / 15(40)$ & $4 / 15(27)$ \\
6 & $8 / 15(53)$ & $6 / 15(40)$ \\
9 & $9 / 15(60)$ & $12 / 15(80)$ \\
12 & $10 / 10(100)$ & $10 / 10(100)$ \\
15 & $15 / 15(100)$ & $15 / 15(100)$ \\
24 & $15 / 15(100)$ & $15 / 15(100)$ \\
\hline
\end{tabular}

a AAP was determined by allowing a group of eight whiteflies/plant for various times on ToLCGV-[Var]-infected tomato plants, followed by a 24-h IAP on virus-free test plants. IAP was determined by allowing whiteflies (eight per plant), after a 24-h AAP on ToLCGV-[Var]-infected tomato plants with various IAPs (as mentioned), on virus-free tomato plants.

${ }^{b}$ Number of plants showing leaf curl symptoms/total number of inoculated plants. Figures in parenthesis indicate transmission efficiency. ful transmission of the virus was achieved routinely when the insects were allowed AAPs of 1, 3, 6, 9, 12, 15, or $24 \mathrm{~h}$. It is clear from Table 2 that with the increase in AAP, there is an increase in transmission efficiency. Similarly, whiteflies could not transmit ToLCGV-[Var] after a 24-h AAP when the IAP was $0.5 \mathrm{~h}$. However, longer IAPs of $1,3,6,9,12,15$, or $24 \mathrm{~h}$ after a 24-h AAP did result in transmission (Table 2). With an AAP of $12 \mathrm{~h}$ followed by $24 \mathrm{~h}$ IAP, $100 \%$ transmission was observed. Similarly, following a 24-h AAP, an IAP of $12 \mathrm{~h}$ was necessary for all plant transmission.

In a single adult whitefly, ToLCGV-[Var] could persist up to 10 days as observed by the development of typical ToLCGV-[Var] symptoms on tomato cv. Pusa Ruby seedlings (Table 3). When single whiteflies were tested for efficiency to transmit the virus for 12 consecutive days, it was observed that transmission of ToLCGV-[Var] was intermittent. In most cases, transmission stopped 1 to 2 days before the death of the insect.

Cloning and infectivity. In November 2001, a severe leaf curl disease of tomato was observed surrounding tomato-growing areas in the Varanasi and Mirzapur districts of eastern Uttar Pradesh, causing $100 \%$ yield losses (Fig. 1A). In these samples, a Begomovirus infection initially was detected by PCR using degenerate primers (25). The causal virus could be transmitted successfully to tomato cv. Punjab Chuhara both by whiteflies and through grafting. Eight full-length clones were obtained from artificially infected young tomato cv. Punjab Chuhara plants showing typical symptoms of the disease. Cross-hybridization among the eight ToLCGV-[Var] clones, partial sequencing of several clones, and sequence comparison with other begomoviruses revealed that three clones belonged to DNA-A (at HindIII sites) and five clones to DNA-B (at XbaI sites) (data not shown). All eight clones were obtained from the same sample. Restriction mapping revealed that DNA-A clones fell into one category while variation among DNA-B clones was observed at the EcoRI site. Arbitrarily, one DNA-A clone (pSCHA1) and two DNA-B clones (pSCXB1 and pSCXB2) were selected for further infectivity analysis.

Partial tandem repeats of DNA-A and DNA-B (either alone or together in combination) were inoculated onto $N$. benthamiana and tomato cv. Organ Spring. On N. benthamiana, systemic symptoms appeared as downward leaf curling within 6 dpi and on tomato within 7 dpi (Table 4) when DNA-A(pTGVA) and DNA-B (pTGVB1) were inoculated together. On N. benthamiana, infected plants exhibited typical downward and upward leaf curling, enlarged veins, puckering of the leaves with interveinal chlorosis, and stunted growth 14 dpi (Fig. 1D). On tomato cv. Organ Spring, yellowing of leaf lamina, leaf curling, and leaf surface reduction along with stunted growth was observed 14 dpi (Fig. 1B). The DNA combination (pTGVA and pTGVB1) could infect other tomato cultivars such as Flora Dade, Geneva 11, and Geneva 790, inducing similar symptoms as manifested on cv. Organ Spring (Table 4). On tobacco cv. Xanthi, symptoms appeared within

TABLE 3. Persistence of Tomato leaf curl Gujarat virus-[Varanasi] (ToLCGV-[Var]) in single whiteflies after 24-h acquisition access period (AAP) on infected tomato cv. Pusa Ruby

\begin{tabular}{|c|c|c|c|c|c|c|c|c|c|c|c|c|}
\hline \multirow[b]{2}{*}{ Experiment no. } & \multicolumn{12}{|c|}{ Serial transfer days ${ }^{a}$} \\
\hline & 1 & 2 & 3 & 4 & 5 & 6 & 7 & 8 & 9 & 10 & 11 & 12 \\
\hline 1 & + & + & + & + & + & + & - & + & + & + & $\mathrm{D}$ & $\ldots$ \\
\hline 2 & + & + & + & + & - & $\mathrm{D}$ & $\ldots$ & $\ldots$ & $\ldots$ & $\ldots$ & $\ldots$ & $\ldots$ \\
\hline 3 & - & - & - & - & - & - & - & - & - & - & $\mathrm{D}$ & $\ldots$ \\
\hline 4 & + & + & + & + & + & - & $\mathrm{D}$ & $\ldots$ & $\ldots$ & $\ldots$ & $\ldots$ & $\ldots$ \\
\hline 5 & + & + & + & + & + & + & + & + & + & + & $\mathrm{D}$ & $\ldots$ \\
\hline 6 & + & + & + & + & + & + & + & + & - & $\mathrm{D}$ & $\ldots$ & $\ldots$ \\
\hline 7 & + & + & + & + & + & + & + & + & + & + & $\mathrm{D}$ & $\ldots$ \\
\hline 8 & + & + & + & - & + & + & + & + & + & $\mathrm{D}$ & $\ldots$ & $\ldots$ \\
\hline 9 & - & + & + & + & + & - & D & $\ldots$ & $\ldots$ & $\ldots$ & $\ldots$ & $\ldots$ \\
\hline 10 & - & - & + & + & - & $\mathrm{D}$ & $\ldots$ & $\ldots$ & $\ldots$ & $\ldots$ & $\ldots$ & $\ldots$ \\
\hline
\end{tabular}

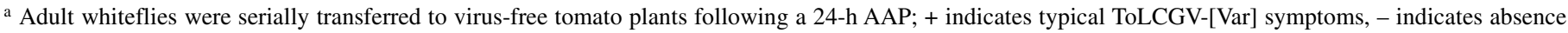
of symptoms, and D indicates whitefly death. 
6 dpi; infected plants showed chlorotic spots and leaf curling, and finally developed severe mosaic and vein-banding symptoms, but were not stunted (Fig. 1E). Tandemly repeated constructs also could infect pepper cv. California Wonder and resulted in leaf curling, interveinal chlorosis, and stunted growth (Fig. 1C). However, DNA-A (pTGVA) and DNA-B (pTGVB1) constructs could not infect other plant species such as bean ( $P$. vulgaris), okra $(A$. esculentus), cotton (G. hirsutum), and N. glutinosa (Table 4). No symptoms were observed on these test plants and no viral DNA was detected by PCR in the DNA extracts from these asymptomatic plants.

DNA-A alone infected $N$. benthamiana (upward leaf curling, big veins), L. esculentum cv. Organ Spring (leaf curling, mild leaf yellowing), and N. tabacum cv. Xanthi (mild mosaic) (Table 4), but symptoms were milder compared with infection by both pTGVA and pTGVB1 in combination and took a much longer time to develop (18 days for $N$. benthamiana, 30 days for tomato, and 23 days for $N$. tabacum cv. Xanthi) when inoculated by particle bombardment. In all of the cases, the presence and absence of ToLCGV-[Var] DNA was determined by PCR with specific primers (GAv50/GAc1122 combination for DNA-A detection and GBv74/GBc1280 combination for DNA-B detection).

When the tandemly repeated constructs of DNA-A and DNA-B of ToLCGV-[Var] were mixed and mechanically inoculated onto $N$. benthamiana and tomato cv. Organ Spring, symptoms developed on the test plants (data not shown). The symptoms were identical to those associated with the bombarded DNAs in these respective hosts. When test plants were inoculated with ToLCGV[Var]-infected sap (previously bombarded with the tandem dimer constructs of pTGVA and pTGVB1), plant species such as $N$. benthamiana, tomato cv. Organ Spring, N. tabacum cv. Xanthi, and pepper cv. California Wonder developed symptoms typical of ToLCGV-[Var] infection resulting from particle bombardment inoculation. However, the incubation period was slightly longer than when cloned DNAs were introduced through particle bombardment. Attempts to mechanically transmit ToLCGV-[Var] from tomato to okra, cotton, $N$. glutinosa, and bean were unsuccessful in three separate experiments.

Genome organization of ToLCGV-[Var]. Complete nucleotide sequences of clones pSCHA1 and pSCXB1 were determined in both orientations. Clone pSCXB2 was not sequenced because the plants developed symptoms similar to pSCXB1 after bombardment with DNA-A tandemly repeated clones. The complete nucleotide sequences of ToLCGV-[Var] DNA-A and DNA-B were determined to be 2,757 and 2,688 nt, respectively.

The genome organization of ToLCGV-[Var] DNA-A resembles other begomoviruses, having two ORFs on the virion strand and four on the complementary strand. The genome organization of ToLCGV-[Var] DNA-B also resembles other bipartite begomoviruses, having two ORFs, one on the viral strand and the other on the complementary strand (data not shown). The ORFs on the virion and complementary strands are named following the accepted nomenclature.

Molecular relationship of ToLCGV-[Var] to other begomoviruses. Complete DNA-A sequence. In all, 71 isolates representing 64 Begomovirus spp. were used for this analysis. When the complete DNA-A sequence was considered, the three members of the new species, ToLCGV-(Vadodara)-[Vad], ToLCGV[Var], and ToLCGV-(Mirzapur)-[Mir], formed a closely related cluster (97 to $99 \%$ nucleotide identity) and shared a considerable identity $( \pm 84 \%)$ with ToLCKV (isolated $\approx 1,500 \mathrm{~km}$ from Varanasi) (Fig. 2). These viruses are more closely related to Old World begomoviruses than to New World viruses (data not shown), with the notable exception of Mungbean yellow mosaic virus (MYMV) and Mungbean yellow mosaic Indian virus (MYMIV), which are most distantly related to ToLCGV-[Var], sharing only 56\% nucleotide identity. ToLCGV-[Var] shares 98\% identity with ToLCGV[Mir] (another isolate from Varanasi), followed by 97\% with ToLCGV-[Vad], the isolate from Gujarat (900 km from Varanasi) (Fig. 3). According to the ICTV guidelines for species demarcation in the genus Geminivirus (9), these three isolates belong to the same species and are distinctly different from virus isolates representing all other Geminivirus spp. reported to date.

Nucleotide sequences of complete DNA-A were compared with those of 21 begomoviruses originating from Asia, representing the "top" of the dendrogram in the previous comparison. The pairwise percentage identities of DNA-A sequences is shown in Table 5. ToLCGV-[Var] had an overall DNA-A component sequence identity of 64 to $84 \%$ with the Asian begomoviruses. Among the six Indian Begomovirus spp. compared, ToLCGV-[Var] shared a maximum identity of $84 \%$ with ToLCKV and least sequence identity with Squash leaf curl China virus (SLCCNV; 64\%).

TABLE 4. Biolistic inoculation of selected plant species with cloned tandemly repeated copies of Tomato leaf curl Gujarat virus-[Varanasi] isolate components

\begin{tabular}{|c|c|c|c|c|c|}
\hline \multirow[b]{2}{*}{ Plant, constructs } & \multirow[b]{2}{*}{ Infected/inoculated ${ }^{\mathrm{b}}$} & \multirow[b]{2}{*}{ Symptom $^{\mathrm{c}}$} & \multirow[b]{2}{*}{ Latent (days) ${ }^{\mathrm{d}}$} & \multicolumn{2}{|c|}{ PCR results ${ }^{\mathrm{a}}$} \\
\hline & & & & DNA-A & DNA-B \\
\hline \multicolumn{6}{|l|}{ DNA-A (pTGVA) alone } \\
\hline Nicotiana benthamiana & $12 / 15$ & LC, BV, LD & 18 & + & - \\
\hline Tomato (Lycopersicon esculentum cv. Organ Spring) & $9 / 15$ & LC, MY & 30 & + & - \\
\hline N. tabacum cv. Xanthi & $9 / 15$ & MiMO & 23 & + & - \\
\hline \multicolumn{6}{|l|}{ DNA-A (pTGVA) and DNA-B (pTGVB2) } \\
\hline N. benthamiana & $14 / 15$ & LC, IVCL, LD, Chls, St, Bls, SL & 6 & + & + \\
\hline \multicolumn{6}{|l|}{ DNA-A (pTGVA) and DNA-B (pTGVB1) } \\
\hline Tomato (L. esculentum) cv. Organ Spring & $18 / 22$ & LC, CR, LR, YL, St & 7 & + & + \\
\hline Tomato (L. esculentum) cv. Flora Dade & $12 / 15$ & LC, VB, LD, St, YL & 7 & + & + \\
\hline Tomato (L. esculentum) cv. Geneva 11 & $13 / 15$ & $\mathrm{LC}, \mathrm{LR}, \mathrm{St}, \mathrm{YL}$ & 7 & + & + \\
\hline Tomato (L. esculentum) cv. Geneva 790 & $12 / 15$ & $\mathrm{YL}, \mathrm{St}$ & 7 & + & + \\
\hline N. benthamiana & $23 / 26$ & LC, IVCL, CR, LD, ChIs, St, Bls, SL & 6 & + & + \\
\hline N. tabacum cv. Xanthi & $13 / 15$ & MO, VB,Chls & 6 & + & + \\
\hline N. glutinosa & 0 & $\ldots$ & $\ldots$ & - & - \\
\hline Pepper (Capsicum апnиum) cv. California Wonder & $13 / 15$ & LC, IVCL, St, Bls & 10 & + & + \\
\hline Bean (Phaseolus vulgaris) cv. Improved Tender Green & $0 / 15$ & $\ldots$ & $\ldots$ & - & - \\
\hline Cotton (Gossypium hirsutum) cv. Stanville & $0 / 15$ & $\ldots$ & $\ldots$ & - & - \\
\hline Okra (Abelmoschus esculentus) cv. Dwarf Green & $0 / 15$ & $\ldots$ & $\ldots$ & - & - \\
\hline \multicolumn{6}{|c|}{$\begin{array}{l}\mathrm{PCR}=\text { polymerase chain reaction. } \\
\text { Number of plants infected/inoculated. } \\
\mathrm{LC}=\text { leaf curling, } \mathrm{BV}=\text { big veins, } \mathrm{MY}=\text { mild yellowing, } \mathrm{YL}=\text { yellow leaf lamina, } \mathrm{St}=\text { stunting, } \mathrm{LD}=\text { leaf distortion, } \mathrm{VB}=\text { vein banding, } \mathrm{MO}=\text { severe } \\
\text { mosaic, } \mathrm{LR}=\text { leaf rolling, } \mathrm{Bls}=\text { blistering, } \mathrm{SL}=\text { small leaves, } \mathrm{CR}=\text { leaf crinkling, } \mathrm{IVCL}=\text { interveinal chlorosis, Chls }=\text { chlorotic spots, and MiMO }=\text { mild } \\
\text { mosaic. }\end{array}$} \\
\hline
\end{tabular}

Vol. 93, No. 12, 2003 


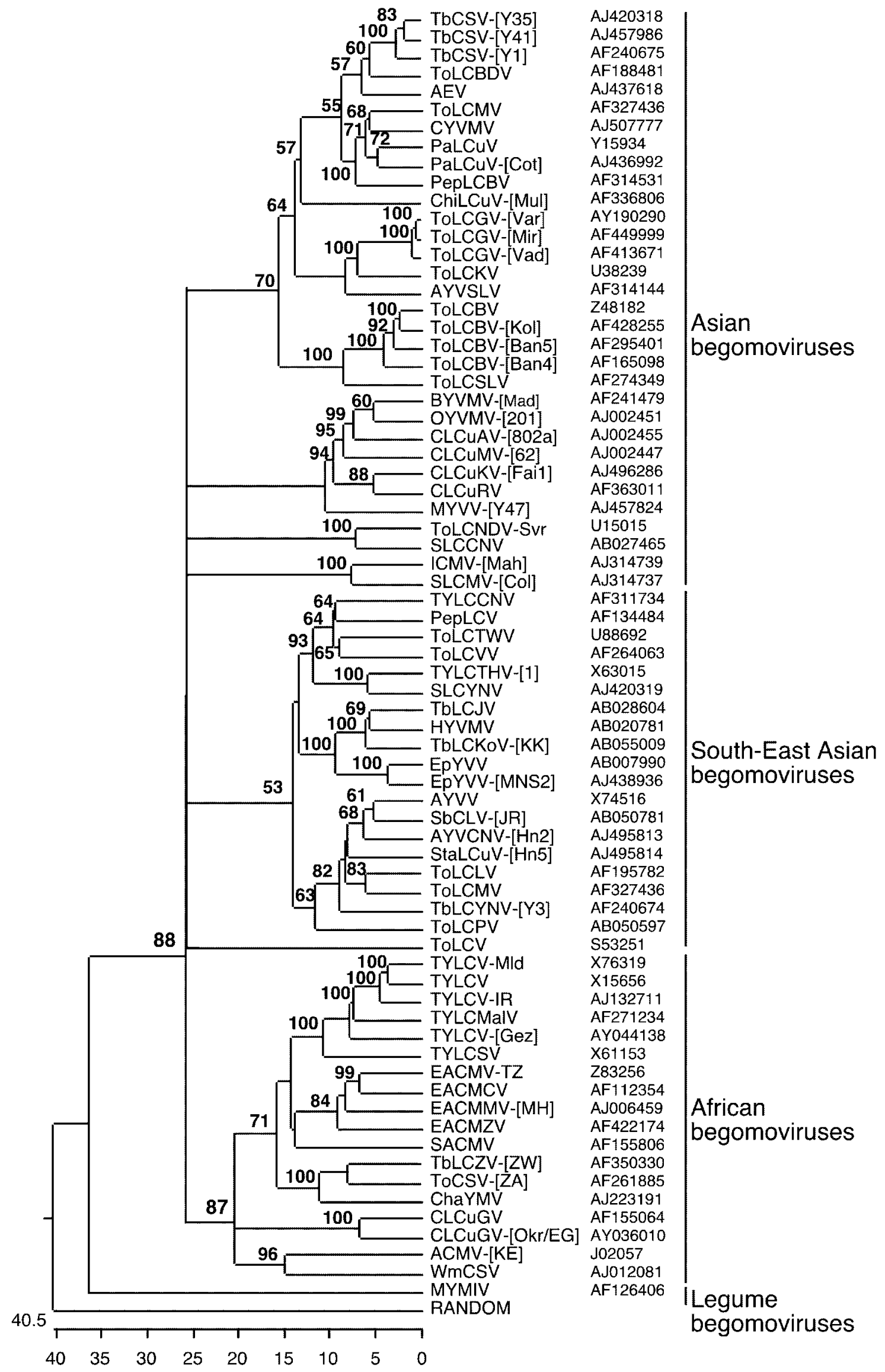

Fig. 2. Dendrogram based on complete DNA A component nucleotide sequences of 71 geminivirus isolates representing 64 species of geminiviruses. Sequences were aligned using the clustal algorithm (MegAlign 3.11, DNAstar) and the bootstrap analysis was done with PAUP 4.0. The vertical axis is arbitrary and the horizontal axis represents a distance expressed in percentage of nucleotide substitution $\times 100$. Dendrograms presented are $50 \%$ majority rule, with nodes bearing less than $50 \%$ bootstrap support collapsed to polytomies. GenBank accession numbers are indicated to the right of each virus acronym. 
When compared with the previously reported tomato-infecting Begomovirus spp. causing TLCD in Asia, DNA-A shared $72 \%$ identity with ToLCBV, 78\% with Tomato leaf curl Bangladesh virus (ToLCBDV), $76 \%$ with Tomato leaf curl Malaysia virus (ToLCMV), and $72 \%$ with Tomato leaf curl Sri Lanka virus (ToLCSLV). It shared less identity with the DNA-A of another bipartite species of TLCD from North India, Tomato leaf curl New Delhi virus-Severe (ToLCNDV-Svr) (66\% identity).

ORF sequence comparisons. The AC1 ORF showed a range of sequence identity among begomoviruses with a minimum of $70 \%$ with Cotton leaf curl Alabad virus-[802a] (CLCuAV-[802a]) and maximum of $92 \%$ with ToLCKV. The putative product of $\mathrm{AC} 1$ also had high sequence identity with the corresponding ORF from the begomoviruses studied and the maximum percentage identity was with ToLCKV. The ORF AC2 showed maximum sequence identity (85 to 90\%) with Tobacco curly shoot virus-[Y1] (TbCSV-[Y1]), Chilli leaf curl virus-[Multan] (ChiLCuV-[Mul]), Pepper leaf curl Bangladesh virus (PepLCBV), Papaya leaf curl virus (PaLCuV), Ageratum enation virus (AEV), ToLCBV, Cotton leaf curl Kokhran virus-[Faisalabad1] (CLCuKV-[Fai1]), and
Croton yellow vein mosaic virus (CYVMV) in their respective order. The product of AC2 shared minimum identity of $53 \%$ with SLCCNV. Similarly, both ORF AC3 and the putative deduced amino acid product shared minimum identity with SLCCNV of 62 and $57 \%$, respectively. ToLCKV showed maximum identity (93\%) for the ORF AC4, whereas the products of AC4 showed a minimum of $31 \%$ identity with PepLCBV. Overall, the IR of DNA-A showed a lesser degree of identity with the Asian geminiviruses (maximum being $77 \%$ with ToLCKV), followed by AEV (70\%). The minimum IR sequence identity (38\%) was observed with the Cotton leaf curl Multan virus-[62] (CLCuMV-[62]), followed by SLCCNV (39\%). Although the ORF AV1 showed a range of nucleotide sequence identity (68 to $84 \%$ ) with the compared begomoviruses, the product of AV1 showed the lowest identity (76\%) with Ageratum yellow vein Sri Lanka virus (AYVSLV) compared with $96 \%$ with CYVMV. The ORF AV2 showed variability in nucleotide identity when compared with the begomoviruses (ranging from 71 to $91 \%$ ) (Table 5).

DNA-B sequence comparisons. When comparing the three Indian geminiviruses for which DNA-B sequences are available,

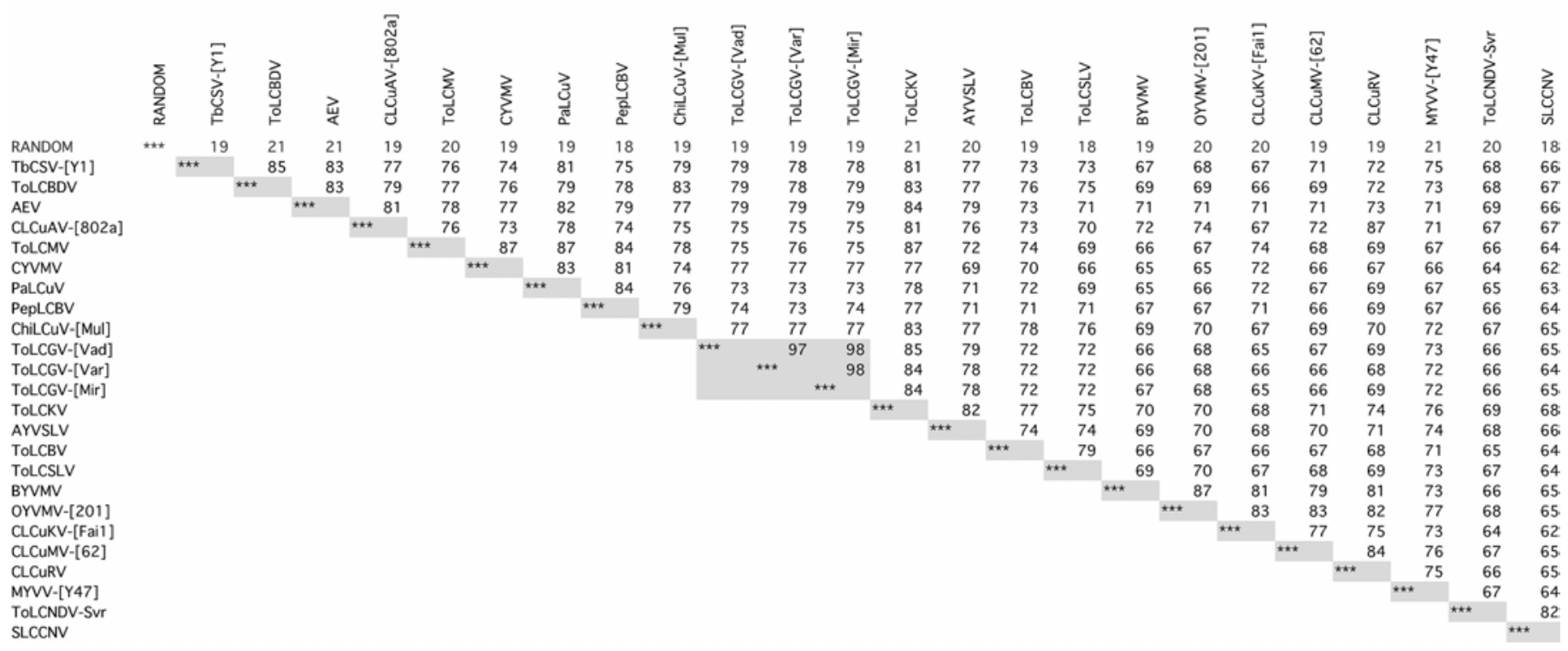

Fig. 3. Matrix of pairwise identity percentages of A component sequences of 24 geminiviruses originating from Asia. Nucleotide sequences were obtained from GenBank and acronyms are followed as per ICTV guidelines (9). The matrix was generated using the clustal algorithm (MegAlign 3.11, DNAstar).

TABLE 5. Percent identity (nucleotide) among DNA-A of Tomato leaf curl Gujarat virus-[Varanasi] isolate with selected begomoviruses originating in Asia ${ }^{a}$

\begin{tabular}{|c|c|c|c|c|c|c|c|c|}
\hline Begomoviruses & DNA-A & ACI & $\mathrm{AC} 2$ & AC3 & $\mathrm{AC} 4$ & AVI & AV2 & ICR (DNA-A) \\
\hline AEV & 79 & $\underline{81(84)}$ & $\underline{88(79)}$ & $\underline{81(79)}$ & $71(50)$ & $75(80)$ & $\underline{89(83)}$ & $\underline{82}$ \\
\hline AYVSLV & 77 & $\underline{89(72)}$ & $\underline{82(76)}$ & $77(76)$ & $94(85)$ & $72(76)$ & $79(79)$ & $\underline{81}$ \\
\hline BYVMV & 66 & $71(78)$ & $70(62)$ & $71(68)$ & $64(42)$ & $70(78)$ & $71(66)$ & 58 \\
\hline CLCuAV-[802a] & 75 & $\overline{70(74)}$ & $72(63)$ & $68(68)$ & $61(34)$ & $69(78)$ & $\overline{70(66)}$ & 61 \\
\hline CLCuKV-[Fai1] & 66 & $79(83)$ & $91(86)$ & $\underline{82(79)}$ & $66(46)$ & $73(81)$ & $\underline{86(84)}$ & 55 \\
\hline CLCuMV-[62] & 66 & $73(77)$ & $\overline{73(65)}$ & $\overline{69(64)}$ & $68(50)$ & $68(79)$ & $71(71)$ & 41 \\
\hline CLCuRV & 68 & $76(81)$ & $72(64)$ & $69(65)$ & $65(46)$ & $68(79)$ & $71(66)$ & 57 \\
\hline OYVMV-[201] & 68 & $75(80)$ & $71(62)$ & $70(66)$ & $66(47)$ & $69(78)$ & $72(66)$ & 58 \\
\hline PaLCuV & 73 & $72(74)$ & $\underline{88(79)}$ & $\underline{81(77)}$ & $58(35)$ & $73(80)$ & $89(82)$ & 54 \\
\hline PepLCBV & 73 & $73(75)$ & $\underline{87(84)}$ & $\underline{83(78)}$ & $60(31)$ & $73(81)$ & $\underline{86(86)}$ & 58 \\
\hline SLCCNV & 64 & $71(76)$ & $64(53)$ & $62(57)$ & $74(58)$ & $74(78)$ & $73(71)$ & 52 \\
\hline TbCSV-[Y1] & 78 & $\underline{83(81)}$ & $\underline{85(77)}$ & $\underline{83(80)}$ & $92(83)$ & $74(78)$ & $\underline{89(84)}$ & 59 \\
\hline ToLCBDV & 78 & $85(86)$ & $87(82)$ & $81(79)$ & $85(77)$ & $74(80)$ & $91(87)$ & 54 \\
\hline ToLCBV & 72 & $\overline{79(84)}$ & $89(84)$ & $81(77)$ & $85(78)$ & $68(74)$ & $\overline{70(71)}$ & 54 \\
\hline
\end{tabular}

${ }^{a}$ Figures in parenthesis indicate putative deduced amino acid sequence identity. Nucleotide identity over $80 \%$ is underlined. 
TABLE 6. Percent identity (nucleotide) among DNA-B of Tomato leaf curl Gujarat virus-[Varanasi] (ToLCGV-[Var]) isolate with selected Indian begomoviruses $^{\mathrm{a}}$

\begin{tabular}{lcccc}
\hline Begomoviruses $^{\mathrm{b}}$ & DNA-B & CR (DNA-B) & BV1 & BC1 \\
\hline MYMIV (AF142440) & 28 & 28 & $28(23)$ & $27(40)$ \\
ToLCNDV (U15016) & $\underline{80}$ & $\underline{90}$ & $\underline{88(90)}$ & $\underline{88(89)}$ \\
ToLCNDV-[Luc] (X89653) & $\mathbf{7 5}$ & $\underline{94}$ & $\underline{86(82)}$ & $\underline{92(95)}$ \\
\hline
\end{tabular}

${ }^{a}$ Figures in parenthesis indicate putative deduced amino acid sequence identity. Nucleotide identity over $80 \%$ is underlined.

${ }^{\mathrm{b}}$ Mungbean yellow mosaic Indian virus (MYMIV) and Tomato leaf curl New Delhi virus from New Delhi (ToLCNDV) and from Lucknow (ToLCNDV[Luc]).
ToLCGV-[Var] shared a high degree of identity with ToLCNDV $(80 \%)$ and ToLCNDV-[Luc] $(75 \%)$, but the least $(28 \%)$ with MYMIV (Table 6). Products of the BV1 and BC1 ORFs of ToLCGV-[Var] showed a high degree of identity with the North Indian ToLCV isolates, ToLCNDV and ToLCNDV-[Luc] (ranging from 82 to $95 \%$ ) and the least to MYMIV (Table 6). ToLCNDV, ToLCNDV-[Luc], and ToLCGV-[Var] are closely related (86 to $90 \%$ ) and have the same pairwise comparison profile all along their genomes (Fig. 4B). These viruses clearly are more differentiated than similar isolates such as TYLCTHV-[1] and TYLCTHV-[2] (Fig. 4B, bottom), and they could be considered different strains based on $\mathrm{B}$ component identities.

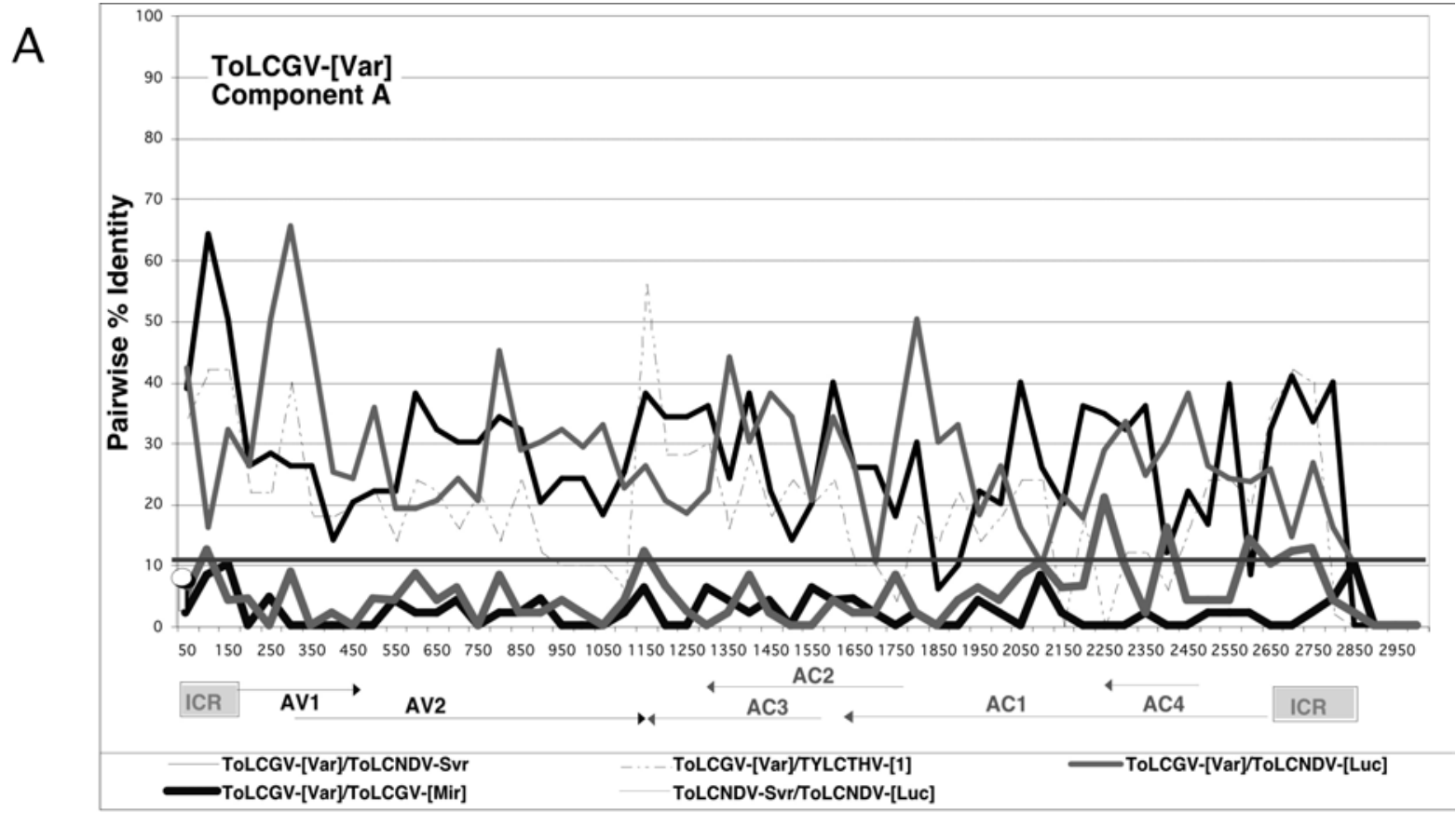

B

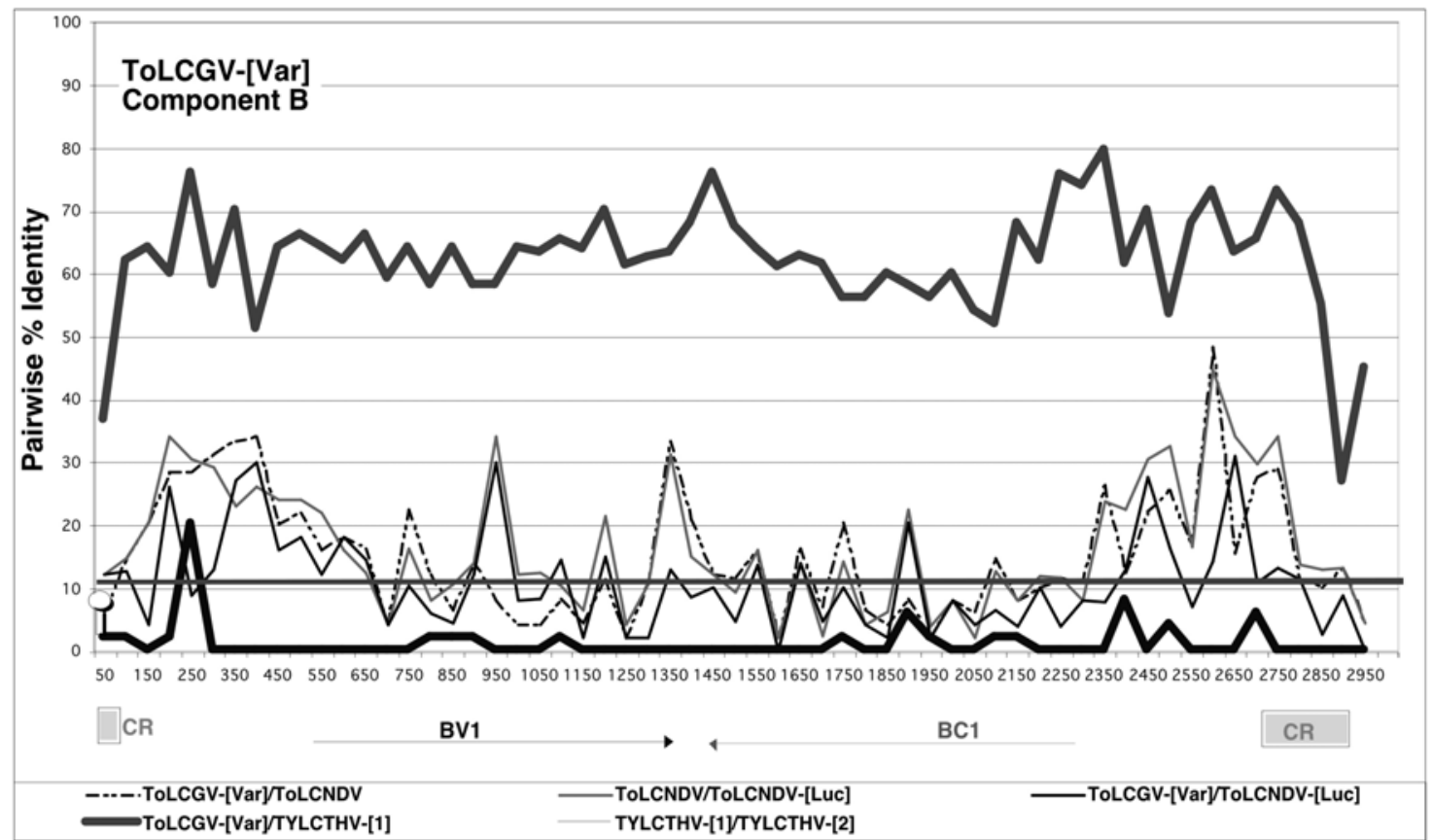

Fig. 4. Pairwise sequence comparison among selected tomato leaf curl viruses. A, Comparison of Tomato leaf curl Gujarat virus (ToLCGV; strains Varanasi, Vadodara, and Mirzapur) DNA-A with Tomato leaf curl New Delhi virus (ToLCNDV; strains Severe and Lucknow) and Tomato yellow leaf curl Thailand virus (TYLCTHV; strains 1 and 2). B, Comparison of DNA-B of ToLCGV-[Var] with TYLCTHV (strains 1 and 2), and ToLCNDV (strains Severe and Lucknow). Positions of the regions in the genomes are represented at the bottom of each figure with the stem-loop motif at the left of the drawing. 
Intercistronic region comparisons. The replication of the $\mathrm{B}$ component by the Rep of the A component is possible because of the existence of the so-called "common region" (CR), a short stretch of $\pm 200 \mathrm{nt}$ that usually is highly conserved between the two molecules. The CR of the DNA-A (CRA) of the three A components of the ToLCGV isolates are very closely related, with 89 to $99 \%$ identity (data not shown). The ToLCGV-[Var] CRA and CRB1 are only $60 \%$ identical, which is an extremely low identity and suggests that they belong to two different species of geminiviruses. The $\mathrm{CR}$ of the $\mathrm{B}$ component (pSCXB1) of ToLCGV-[Var] is closely related to the available CRA and CRB sequences of the ToLCNDV isolates (between 81 and 90\%), indicating that these sequences could pertain to isolates of the same species. The CRAs of the isolates of ToLCGV also are related to AEV, ToLCKV, and AYVSLV with 82 to $77 \%$ identities, whereas these sequences are 41 to $65 \%$ identical to all the other Asian viruses tested here (Table 5). A multiple alignment of the CRs and intercistronic regions (ICRs) of the 22 viruses studied here and several strains of ToLCNDV and ToLCGV is shown in Figure 5, where we noticed that all the ToLCGV and ToLCNdV isolates, as well as SLCCNV, ToLCMV, AEV, ToLCKV, and AYVSLV, have similar or very related iteron sequences (GGTGT-XX/X-GGAGT). The exception is the ToLCNDV-Mld and Luffa isolates previously studied (3-5), whose iteron sequence is GGCGT-CT-GGCGT. The major difference is found in the spacer sequence between the two iterons that varies between 2 and $3 \mathrm{nt}$. We also observed that a third identical iteron is present in the $5^{\prime}$ end of the CRs. All the other viruses tested here have very different iterons in both sequence and number (Fig. 5B). ToLCGV and ToLCNDV isolates share more than $85 \%$ identity in the first $80 \mathrm{nt}$ of their CRs, whereas the region between the TATA box and hairpin loop is below 50\% (data not shown). Noticeably, apart from the stem-loop region and the TATA box conserved for all geminiviruses, all the viruses tested here share two short sequences, AATGGCA and TAAT, located in the $5^{\prime}$ end of the region between the TATA box and the stem-loop.

Recombination study with other Asian viruses. Attempts were made to identify the putative recombination sites that occurred between ToLCGV-[Var] and the Asian geminiviruses belonging to the same cluster studied here, through pairwise sequence comparison (Fig. 6). When DNA-A was compared, no recombination was observed among ToLCGV-[Var] with ToLCGV-[Mir] or ToLCGV[Vad] (Fig. 4A). Remarkably, only a short possible recombination (150 nt) was observed between ToLCGV-[Var] DNA-A with ToLCNDV in the $3^{\prime}$ end of AC1 (Fig. 4A). A mapping of the putative recombination events between ToLCGV-[Var] and the 21 Asian begomoviruses considered in this study is represented in Figure 6. For example, when the full lengths of ToLCGV-[Var] and ToLCKV were compared, there was high nucleotide sequence identity for their IR (approximately the first $100 \mathrm{nt}$ ), the $5^{\prime}$ end of AV1 (200 nt), and a long stretch of 1,350 nt from the $5^{\prime}$ end of $\mathrm{AC} 3$ to the $5^{\prime}$ end of the IR. This indicates that, at these sites, recombination events possibly took place between these two tomato-infecting viruses or with a third, unknown virus. Within the subset of viruses studied here, one can recognize two clusters of viruses relative to putative recombinations with ToLCGV-[Var]: the first cluster would comprise the "top" 14 viruses of the dendrogram shown in Figure 6A and would include ToLCGV-[Var], for which there is a substantial amount of recombination culminating in $\approx 60 \%$ of the genome length with ToLCKV; the second cluster includes the "bottom" 8 viruses of the tree and would include ToLCNDV, for which there is little or no apparent recombination with ToLCGV-[Var]. The pattern of these putative recombinations is very similar within the first cluster with two major blocks: the first one in the coat protein $(\mathrm{CP})$ and the second one, with variable lengths, over the AC2-AC1 region of the genome. It is remarkable that, in the case of the $\mathrm{CP}$, the segments look almost identical and are located in the same place in the ORF, possibly indicating biological and structural constraints that may limit recombination or fitness of recombinant genomes. In the first cluster, there are three exceptions to the level and pattern of recombination (i.e., ToLCBV, ToLCSLV, and AYVSLV), and their position in the tree is justified by other putative recombinations between these viruses and other viruses of the same cluster, but not with ToLCGV-[Var].

\section{DISCUSSION}

We have isolated and characterized a new Begomovirus species that is causing a devastating disease of tomato in Varanasi, Uttar Pradesh, India. On the basis of sequence identity of the com-
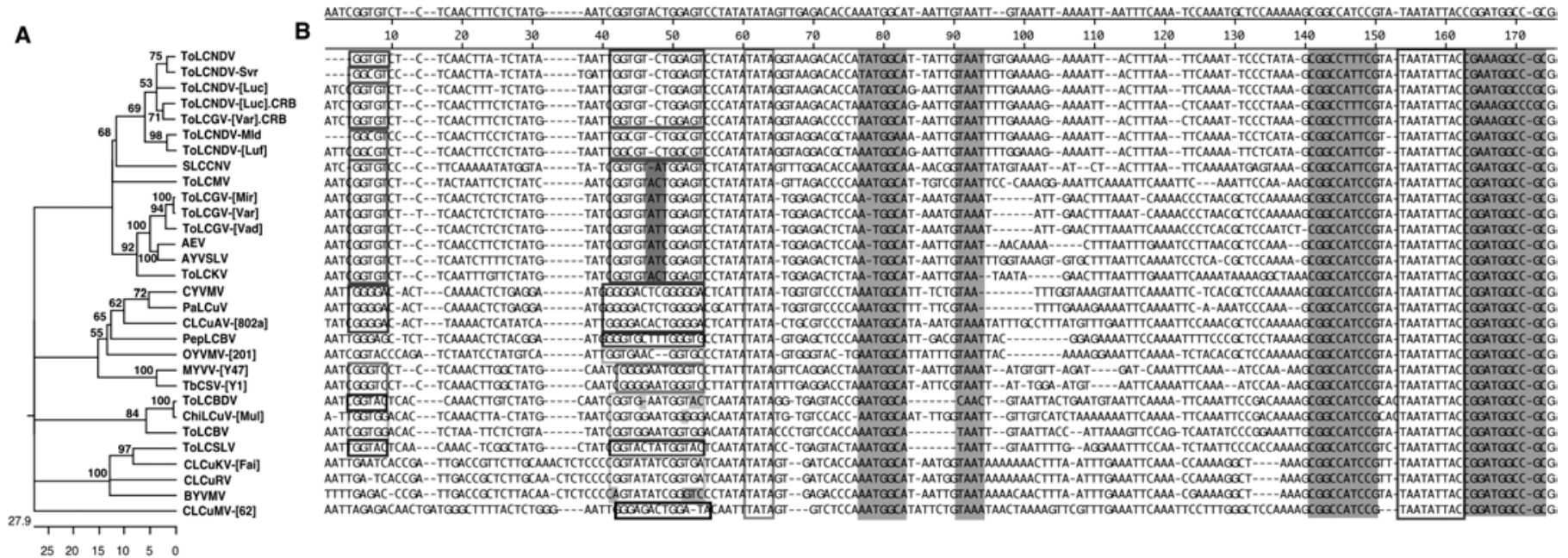

Fig. 5. Diagrammatic representation of the intercistronic region (IR) of Tomato leaf curl Gujarat virus-[Varanasi] (ToLCGV-[Var]) and representatives of other geminiviruses originating from Asia. A, Dendrogram based on IRs nucleotide sequences of 30 geminivirus isolates representing 22 species of geminiviruses. Nucleotide sequences were obtained from GenBank and acronyms are followed as per ICTV guidelines (9). Sequences were aligned using the clustal algorithm (MegAlign 3.11, DNAstar) and the bootstrap analysis was done with PAUP 4.0. The vertical axis is arbitrary and the horizontal axis represents a distance expressed in percentage of nucleotide substitution $\times 100$. Dendrograms presented are $50 \%$ majority rule, with nodes bearing less than $50 \%$ bootstrap support collapsed to polytomies. B, Multiple alignment of IRs nucleotide sequences of 30 geminivirus isolates representing 22 species of geminiviruses. The conserved nonanucleotide sequence is squared and the conserved stem-loop, TATA box and other sequences are boxed in gray, while the iteron sequences are in open boxes. The positions in the multiple alignment are indicated on top of the figure. The multiple alignment was generated using the clustal algorithm (MegAlign 3.11, DNAstar). 
ponent A, and in accordance with the ICTV Geminiviridae StudyGroup guidelines (9), the present virus isolate from Varanasi is considered to be a member of a new Begomovirus species, ToLCGV with the Varanasi isolate designated as ToLCGV-[Var]. ToLCGV-[Var] is transmitted by whiteflies in a persistent manner and, with an increase in AAP and IAP, there is an increase in transmission frequency of the virus. Furthermore, like other WTGs, ToLCGV-[Var] could be serially transmitted for up to 10 days by a single infectious whitefly. Overall, the whitefly transmission parameters of ToLCGV-[Var] are similar to those of ToLCBV-[Ban4] (16).

Full-length DNA-A and DNA-B components of ToLCGV-[Var] from tomato were cloned and infectivity of the clones was demonstrated. ToLCGV-[Var] DNA-A has characteristics of a monopartite and bipartite Begomovirus species. In the absence of DNA-B, DNA-A can induce leaf curling, vein swelling, and leaf distortions on $N$. benthamiana and leaf curling on tomato. Although DNA-A alone is infectious and produces mild and delayed symptoms on $N$. benthamiana and tomato cv. Organ Spring, the association of DNA-B increases symptom severity and also considerably shortens incubation period. Upon artificial inoculation with cloned DNA-A and DNA-B through particle bombardment, tomato cv. Organ Spring showed symptoms resembling those observed on tomato plants under field conditions. DNA-A of another Begomovirus species reported from Bangalore, ToLCKV, also was infectious on $N$. benthamiana and tomato (2), but no DNA-B association has been demonstrated. In both ToLCGV-[Var] and Tomato leaf curl Thailand virus, DNA-A alone was shown to be infectious, but DNA-B increased symptom severity (20). ToLCGV-[Var] is sap transmissible and is the only known ToLCV isolate from India to infect pepper (C. annuum cv. California Wonder). Our studies also suggest that ToLCGV-[Var] may be one of the causal agents of the pepper leaf curl disease in this region.

Unexpectedly, ToLCGV-[Var] DNA-A and DNA-B share a common region of $155 \mathrm{bp}$ that is only $60 \%$ identical. We were not able to isolate another A or B component from the infected samples. This suggests that these two molecules are the cognate pair of components that cause the severe disease of tomato under field conditions. The leaf curl disease of tomato is extremely severe in the fields around Varanasi, Uttar Pradesh, India and we identified this B component each time we looked for it in different samples; therefore, it seems that the presence of this DNA-B is a prerequisite for severe symptoms.

The ToLCGV DNA-A sequences available are different from all other begomoviruses. Phylogenetic analysis placed ToLCGV-[Var] in a unique cluster with two other isolates (97 to 99\%), ToLCGV[Vad] from Vadodara and ToLCGV-[Mir] from Mirzapur. This clearly indicates that all three virus isolates belong to the same species, ToLCGV. The closest tomato-infecting Indian geminivirus is ToLCKV, with $84 \%$ identity. ToLCGV is neither closely related to ToLCNDV (66\% nucleotide identity) nor to other tomato viruses from Bangalore (72 to $74 \%$ ).

The ToLCGV-[Var] DNA-B sequence is the only one available so far for this species and, when compared with the B component sequence of ToLCNDV or other viruses, it is clear that this molecule is closely related to the B components of ToLCNDV because they have the same pairwise comparison profile (Fig. 4B) and they share a high level of identity in their CRs (Table 6). From the sequence analysis, it could be concluded that the B component associated with ToLCGV-[Var] DNA-A is, in fact, a ToLCNDV B

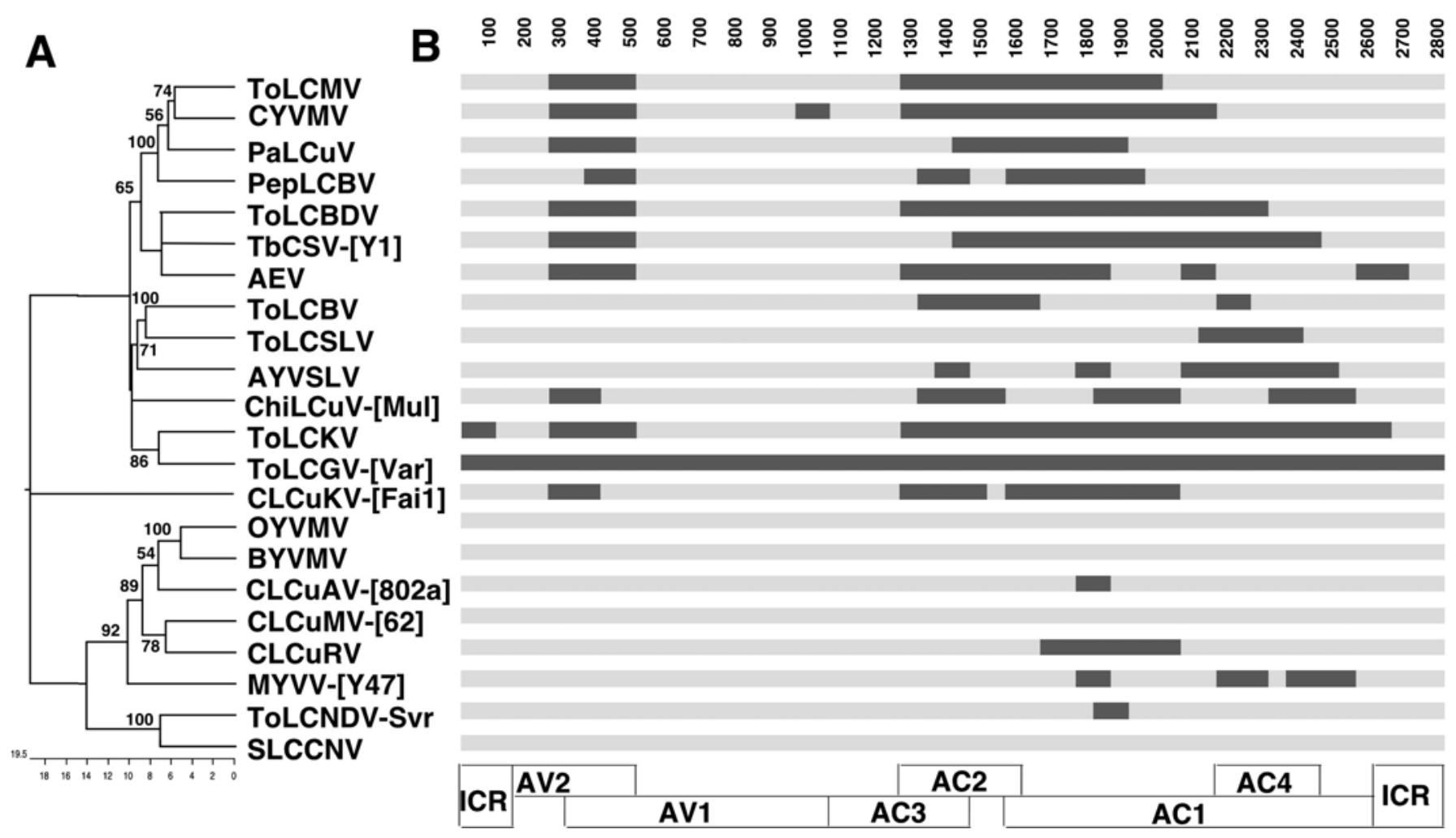

Fig. 6. Diagrammatic representation of recombinant fragments between Tomato leaf curl Gujarat virus-[Varanasi] (ToLCGV-[Var]) and representative of other geminivirus species originating from Asia. A, Dendrogram based on complete DNA-A component nucleotide sequences of 22 geminivirus isolates representing 22 species of geminiviruses. Nucleotide sequences were obtained from GenBank and acronyms are followed as per ICTV guidelines (9). Sequences were aligned using the clustal algorithm (MegAlign 3.11, DNAstar) and the bootstrap analysis was done with PAUP 4.0. The vertical axis is arbitrary and the horizontal axis represents a distance expressed in percentage of nucleotide substitution $\times 100$. Dendrograms presented are 50\% majority rule, with nodes bearing less than $50 \%$ bootstrap support collapsed to polytomies. B, Each line represents a linearized geminivirus genome (in the sense orientation starting from the nicking site in the stem loop, in the common region) and each presence of gray segments indicates homologous stretches of sequences to ToLCGV-[Var] at the strain level (>89\%) within the genome of other Asian geminiviruses. Positions of the regions of the genome are represented at the top of the figure and a representation of a linearized geminivirus genome is represented at the bottom. 
component mobilized by ToLCGV. The fact that the iteron sequences and general organization are the same between the two species makes it possible that one monopartite virus, such as ToLCGV, could mobilize the B component of another species, such as ToLCNDV, despite the fact that they have very different CR sequences. Thus, ToLCGV-[Var] is bipartite, at least de facto, because the $\mathrm{B}$ component increases the symptoms and the rate of movement of the DNA-A in the infected plant.

Begomoviruses appear to have a great capacity to recombine (19). The amount of material that viruses may exchange ranges from small fragments of a few nucleotides to very large fragments of 2,000 nt or more. Recombination among tomato leaf curl viruses originating from Bangalore has been documented $(2,13)$. In this study, a novel method (pairwise sequence analysis) was applied to explore the level of recombination between ToLCGV[Var] DNA-A and other geminiviruses. There was no recombination observed among the three members of the new species (ToLCGV). Furthermore, very little or no recombination (Fig. 4A) could be identified between ToLCGV and ToLCNDV, even though these two viruses must have been in contact if ToLCGV[Var] captured the ToLCNDV B component. On the contrary, ToLCGV shares putative recombinant fragments with 13 different Asian viruses (Fig. 6B), indicating that this virus is very amenable to recombination and that this phenomenon might have played an important role for the evolution of these viruses. A similar conclusion was suggested for both ToLCKV (2) and ToLCBV (13).

We can conclude that ToLCGV is a new Begomovirus species in India, causing very severe diseases of tomato and, possibly, pepper. This virus is a monopartite/bipartite virus that, in addition, has the capacity to mobilize a B component from ToLCNDV, another species of Begomovirus infecting tomato in India. Finally, this virus shares many fragments of its genome with several Asian geminiviruses, confirming that recombination is an essential molecular component for gemininivirus evolution.

\section{ACKNOWLEDGMENTS}

This study was funded by the Donald Danforth Plant Science Center. We thank the Department of Science and Technology, Government of India for granting a BOYSCAST Fellowship to S. Chakraborty to conduct this study; and P. Cosgrove and B. Chattopadhyay for carefully reading and correcting the manuscript.

\section{LITERATURE CITED}

1. Birnboim, H. C., and Doly, J. 1979. A rapid alkaline extraction procedure for screening recombinant plasmid DNA. Nucleic Acids Res. $7: 1513$.

2. Chatchawankanphanich, O., and Maxwell, D. P. 2002. Tomato leaf curl Karnataka virus from Bangalore, India, appears to be a recombinant begomovirus. Phytopathology 92:637-645.

3. Chatterji, A., Beachy, R. N., and Fauquet, C. M. 2001. Expression of the oligomerization domain of the replication-associated protein (Rep) of Tomato leaf curl New Delhi virus interferes with DNA accumulation of heterologous geminiviruses. J. Biol. Chem. 276:25631-25638.

4. Chatterji, A., Chatterji, U., Beachy, R. N., and Fauquet, C. M. 2000. Sequence parameters that determine specificity of binding of the replication-associated protein to its cognate in two strains of Tomato leaf curl virus-New Delhi. Virology 273:341-350.

5. Chatterji, A., Padidam, M., Beachy, R. N., and Fauquet, C. M. 1999. Identification of replication specificity determinance in tomato leaf curl virus from New Delhi. J. Virol. 73:5481-5489.
6. Czosnek, H., Ber, R., Antignus, Y., Cohen, S., Navot, N., and Zamir, D. 1988. Isolation of tomato leaf curl from India. Plant Dis. 77:1168.

7. Dellaporta, S. L., Woods, J., and Hicks, J. B. 1983. A plant DNA minipreparation. Version II. Plant Mol. Biol. Rep. 1:19-21.

8. Dry, I. B., Rigden, J. E., Krake, L. R., Mullineaux, P. M., and Rezaian, M. A. 1993. Nucleotide sequence and genome organization of tomato leaf curl geminivirus. J. Gen. Virol. 74:147-151.

9. Fauquet, C. M., Bisaro, D. M., Briddon, R. W., Brown, J., Harrison, B. D., Rybicki, E. P., Stenger, D. C., and Stanley, J. 2003. Revision of taxonomic criteria for species demarcation in the Geminiviridae family, and an updated list of begomoviral species. Arch. Virol. 148:405421.

10. Green, S. K., and Kalloo, G. 1994. Leaf curl and yellowing viruses of pepper and tomato: An overview. Tech. Bull. No. 21. Asian Vegetable Research Development Center, Taiwan, ROC.

11. Hong, Y. G., and Harrison, B. D. 1995. Nucleotide sequences from tomato leaf curl viruses from different countries: Evidence for three geographically separate branches in the evolution of the coat protein of whitefly-transmitted geminiviruses. J. Gen. Virol. 76:2043-2049.

12. Kheyr-Pour, A., Bendahmane, M., Matzeit, V., Accota, G. P., Crepsi, S., and Gronenborn, B. 1991. The tomato yellow leaf curl virus from Sardinia (TYLCV-S) has a single genomic component. Nucleic Acids Res. 19:6763-6769.

13. Kirthi, N., Maiya, S. P., Murthy, M. R. N., and Savithri, H. S. 2002. Evidence of recombination among the tomato leaf curl strains/species from Bangalore, India. Arch. Virol. 147:255-272.

14. Klein, T. M., Fromm, M. E., Weisinger, A., Tomes, A., Schaff, D., Sletten, M., and Sanford, J. C. 1988. Transfer of foreign genes into intact maize cells using high-velocity microprojectiles. Proc. Natl. Acad. Sci. USA 85:4305-4309.

15. Mayo, M. A., and Pringle, C. R. 1998. Virus taxonomy-1997. J. Gen. Virol. 79:649-657.

16. Muniyappa, V., Venkatesh, H. M., Ramappa, H. K., Kulkarni, R. S., Zeidan, M., Tarba, C. Y., Ghanim, M., and Czosnek, H. 2000. Tomato leaf curl virus from Bangalore (ToLCV-Ban4): Sequence comparison with Indian ToLCV isolates, detection in plants and insects, and vector relationships. Arch. Virol. 145:1583-1598.

17. Navot, N., Pichersky, E., Zeidan, M., Zamir, D., and Czosnek, H. 1991. Tomato yellow leaf virus: A whitefly-transmitted geminivirus with a single genomic component. Virology 185:151-161.

18. Padidam, M., Beachy, R. N., and Fauquet, C. M. 1995. Tomato leaf curl geminivirus from India has a bipartite genome and coat protein is not essential for infectivity. J. Gen. Virol. 76:25-35.

19. Padidam, M., Sawyer, S., and Fauquet, C. M. 1999. Possible emergence of new geminiviruses by frequent recombination. Virology 265:218-224.

20. Rochester, D. E., Kositratana, W., and Beachy, R. N. 1990. Systemic movement and symptom production following agroinoculation with a single DNA of tomato leaf curl geminivirus (Thailand). Virology 178:520-526.

21. Rybicki, E., Briddon, R. W., Brown, J. E., Fauquet, C. M., Maxwell, D. P., Harrison, B. D., Markham, P. G., Bisaro, D. M., Robinson, D., and Stanley, J. 1999. Family Geminiviridae. Pages 285-297 in: Virus Taxonomy. Seventh Report of the International Committee on Taxonomy of Viruses. M. H. van Regenmortel, C. M. Fauquet, D. H. L. Bishop, E. B. Carsten, M. K. Estes, S. M. Lemon, J. Maniloff, M. A. Mayo, D. J. McGeoch, C. R. Pringle, and R. B. Wickner, eds. Academic Press, San Diego, CA.

22. Srivastava, K. M., Hallan, V., Raizada, R. K., Chandra, G., Singh, B. P., and Sane, P. V. 1993. Molecular cloning of Indian tomato leaf curl virus genome following a simple method of concentrating the supercoiled replicative form of viral DNA. J. Virol. Methods 51:297-304.

23. Swofford D. L. 1998. PAUP*. Phylogenetic Analysis Using Parsimony (*and other methods). Version 4. Sinauer Associates, Sunderland, MA.

24. Vasudev, R. S., and Sam Raj, J. 1948. A leaf curl disease of tomato. Phytopathology 38:364-369.

25. Wyatt, S. D., and Brown, J. K. 1996. Detection of sub-group III geminivirus isolates in leaf extracts by degenerate primers and polymerase chain reaction. Phytopathology 86:1288-1293. 